\title{
General introduction and overview to Critical Issues in Human Rights and Development
}

This collection of chapters seeks to bring together leading scholars, practitioners and activists to address the intersecting issues of human rights and development at a time when the world is confronting challenges on a scale that might appear to reduce these two noble goals to wishful thinking. Indeed, the COVID-19 pandemic adds a further dimension to the climate emergency, which already threatens to disrupt the global ecosystem, renders life more precarious, and places the most vulnerable economies in turmoil, exacerbating ethnic tension and inequality. Titling this collection of chapters "critical issues" signifies both that the magnitude of the challenges alluded to above calls for a critical rethinking of the analytical frameworks of human rights and development and that the 18 chapters all are critical in the sense of being essential to understanding whether and how these frameworks can be meaningful and useful as the world seeks to "build back better".

The collection begins with five chapters that seek to capture "intersecting paradigms of human rights and development" in Part I, by which we mean that there are issues of a scope that they embrace all the other issues addressed in the two other parts. Thus, development theory, economic perspectives, gender, climate change and disability are broad concerns that provide the context for all reflection on human rights and development.

The second part explores the complexities of applying the goalposts of human rights and development to the eight specific issues of technology, education, water and sanitation, health, housing, food, information, work and trade. Many others could have been included, such as Indigenous rights, corruption, transparency and good governance, migration, armed conflict and ethnic violence. These issues are all touched upon in various chapters but not dealt with separately. The eight issues covered in Part II are critical issues from the perspective of this book but at the same time illustrative of many other issues.

Part III focuses on four critical approaches to operationalizing human rights in development, namely, accountability, treating development as a human right, indicators and globally agreed-upon development objectives. They con- 
stitute the tools available to advance issues like those in Part II in ways that are meaningful in light of the intersecting paradigms of Part I.

The conclusion examines whether and to what extent the paradigms, issues and tools of human rights and development addressed in the three sections can help people rise above the global threats to human well-being and achieve their full potential as human beings. It summarizes how human rights and development are affected by the four interrelated major challenges facing humanity, namely, the climate emergency, the COVID-19 pandemic, extreme inequality and racial injustice, and the rise or populist leadership and authoritarianism. The most effective responses to these challenges are building consensus on international standards and social mobilization for human rights and sustainable development in order to provide the normative and policy-oriented framing of the problems and the basis for action toward solutions based on justice and the equal value of all human beings.

\section{PART I - THE INTERSECTING PARADIGMS OF HUMAN RIGHTS AND DEVELOPMENT}

\section{Introduction to Part I}

The five chapters in this section of the book provide essential background for the analysis of human rights and development, with the unifying and somewhat ostentatious common theme of "intersecting paradigms". What we mean by that phrase is the set of theories and methodologies reflecting the worldview of those who seek to contribute to the understanding of a particular scientific subject. Thus, development has emerged in the theoretical literature as a broad concept of societal advancement covering the sometimes-contradictory process of growth in gross domestic product (GDP) regardless of the impact on social justice and redistribution and management of resources in ways that advance social justice.

Balakrishnan Rajagopal, a legal scholar who focuses on social justice, development and human rights at the Massachusetts Institute of Technology and is UN Special Rapporteur on the Right to Adequate Housing, examines a wide range of old and new theories of development with a critical perspective on their significance for human rights. He builds on the counter-hegemonic perspective of the Global South through such movements as the World Social Forum as he articulates a critical perspective on prevailing theories of development and formulates a progressive vision of human rights and development that is responsive both to the challenges of shifting geopolitics and to the ethics of solidarity underlying the human rights movement.

Then Stephen Marks, a human rights scholar and activist at Harvard, and Ajay Mahal, a health economist in Australia, tackle the problem of what is 
sometimes perceived as conflicting paradigms of economics and human rights, the former using well-honed tools of understanding production, consumption and transfer of goods and services and the latter being a normative framework for reducing oppression and repression in society. They propose elements of a "common conceptual framework" to overcome the obstacles to a mutually reinforcing dialogue, without any illusions that it will be easy to put it into practice.

The other three chapters in Part I relate to priority global challenges that can only be met by creative and evidence-based approaches to addressing their impact on development and human rights. Throughout human history, power relations between men and women, especially the oppressive nature of patriarchy, have been slow to evolve. Celestine Nyamu Musembi, a specialist in legal anthropology from Kenya, provides a detailed overview of evolving understandings of gender and of legal and policy approaches to women's rights in development, concluding with a sober assessment of prospects for introducing gender justice into the human rights and development agenda. Building on the accomplishments of the Beijing Fourth World Conference on Women and the Convention on the Elimination of All Forms of Discrimination against Women, she proposes a "strategic engagement" approach as preferable to the "hands-off" and "abolition" approaches found in the literature, according to which cultural norms and institutions can provide avenues to advance gender justice.

The fourth chapter is devoted to the second major civilizational challenge, that of climate change, which is addressed by Stephen Humphreys, who had produced pathbreaking work on this topic for the International Council on Human Rights Policy in Geneva and has continued to be a leading authority, including for the Intergovernmental Panel on Climate Change's 1.5 Report, in addition to his functions as a professor at the London School of Economics. He traces the history of efforts to link climate change with human rights and development, identifying areas of complementarity and of friction. In a time of the COVID-19 pandemic, he underscores in conclusion how immense the challenge is to build back with anything approaching equitable redistribution, however necessary such a "favored utopia" might be in addressing climate change.

The final cross-cutting issue is that of persons with disabilities, which is addressed by Michael Stein, the founding director of Harvard Law School's Project on Disability, and Janet E. Lord, senior research fellow in that project. They both participated actively in all stages of the negotiations leading to the adoption of the Convention on the Rights of Persons with Disabilities (CRPD) and have worked and taught on disability inclusive development and disability law reform for many organizations across the globe. Their chapter reviews the history and prospects for the equal inclusion of persons with disabilities 
in rights-based development, highlighting the slow progress, accelerated by the adoption of the CRPD. The cross-cutting nature of disability inclusive development emerges clearly from the call this chapter makes that coherent programs, policies and action, internally and through international cooperation, including responses to the COVID-19 pandemic, are "fully inclusive of persons with disabilities, from design through implementation".

\section{PART II - CRITICAL SOCIAL ISSUES OF DEVELOPMENT FROM A HUMAN RIGHTS PERSPECTIVE}

\section{Introduction to Part II}

Each of the eight issues addressed in this section constitutes a field of development practice that has also been identified as a component of the category of economic, social and cultural rights. Much of development practice involves advancing goals relating to these issues, often without regard to the fact that each has been the object of extensive standard-setting and monitoring as universally accepted human rights. The chapters in this section attempt to bridge the gap between development and human rights theory and practice on these issues.

The first issue is that of technology, a topic that has obvious implications for development - given the extreme disparities between low- and middle-income countries lacking technical expertise and resources and high-income countries that dominate patents and every other indicator of advanced technology - but is not that obvious as a human rights issue, as traditionally conceived. Calestous Juma, Faculty Chair of the Innovation for Economic Development Executive Program at the Harvard Kennedy School, until his untimely death, addresses this issue with the depth of his remarkable background as a world authority on technological innovation in sustainable development. He addresses both the impact of technology transfer on global disparities and on increased access to the benefits of technology. He not only provides a deep understanding of how these processes relate to the human right to benefit from advances in science and technology but also draws the human rights implications of a wide range of relevant standards on intellectual property, climate change and infrastructure development.

David Archer brings to the topic of the right to education unique professional experience for ActionAid and UNESCO, where his ideas on this right have had considerable impact. He not only looks as the evolution of planning to improve education systems and financing, but also citizen action to advance education as a human right, concluding with an eloquent appeal to see education as "one of the most powerful equalizing forces in a society". 
The third theme in this section is water and sanitation. Sharmila L. Murthy, Professor at Suffolk University Law School and leading authority on international environmental law, poverty and human rights, explains the emergence of the rights to water and sanitation by looking at the history and content of these rights before highlighting such issues as the controversy over privatization of water, and a case study in South Africa, water for agriculture, transnational corporation, and dams. She concludes by making a convincing case for cross-sector collaboration of civil society, governments and national and international institutions to address the impact on water and sanitation of challenges such as the COVID-19 pandemic.

The importance of health in human rights and development is undeniable and the team of Lisa and Jeff Sachs bring to this topic the highest level of professional and scholarly engagement. Jeffry Sachs, a world-renowned economist, is University Professor and Director, Center for Sustainable Development at Columbia University and Lisa Sachs, trained in law and economics, is the Director of Columbia's Center on Sustainable Investment. They begin by noting gross disparities in health outcomes notwithstanding the wide acceptance of health as a human right. To explain this reality, they examine the poverty-disease trap, and the role of WHO's Commission on Macroeconomics and Health to attempt to address it, before exploring various modalities of global cooperation to realize the human right to health, including through international law, development cooperation and human rights procedures. They conclude by arguing why it is urgent to scale up efforts, building on international human rights commitments, to achieve the health goals of the SDG within the 2015-2030 timeframe.

The topic of housing and land is addressed by the first Special Rapporteur on the Right to Adequate Housing, Miloon Kothari, a leading activist on this topic, who not only reviews the normative developments on this right within the UN system, but links the right to housing to the recognition and protection of the right to land. Both of these rights are all the more urgent to respond to massive homelessness and evictions as a result of the COVID-19 pandemic. Inequitable access to housing and land ownership, he points out, cannot be separated from a host of interrelated problems ranging from lack of livelihood options, to poor health, hunger and food insecurity, and acute poverty.

A closely related right is that to food and nutrition, which Deborah Hines addresses from her unique perspective as a leading specialist in food and nutrition security policy and strategy development, having worked with the World Food Programme, the Food and Agriculture Organization and numerous other global, bilateral and nongovernmental institutions. She not only examines the international legal status of the right to adequate food and nutrition but also argues that hunger is neither inevitable nor acceptable, but rather the result of inaction or of harmful actions. Given that development and 
the right to food must operate as mutually reinforcing strategies, she explains how a rights-based approach offers a platform for advocacy, and coordinating, planning, implementation, monitoring and evaluating efforts aimed at eradicating hunger and achieving equitable food and nutrition security.

The right to information (RTI) is the only topic in this section to be addressed from the perspective of the experience in one country and in this case Aruna Roy and Suchi Pande not only bring their unique experience as civil society advocates to bear on understanding how India has addressed information as a human right but also the broader implications for human rights and development. They focus on the impact of poor governance on transparency and accountability and document the framing and content of the right as well as the exemplary character of protection of the RTI in India as "law making from below".

In the final chapter in this section, Gerry Rodgers, a development economist with a long career in the International Labour Organisation, represents the extraordinary value of bringing the perspective of a leading professional to review the nature and significance of work and conditions of work in human rights and development. After reviewing the normative content of the right to work and the connection with poverty and development, he examines the prospects for the realization of this right consistent with the ILO's notion of decent work and the SDG 8 and the related economic and political challenges and the response to the COVID-19 pandemic.

\section{PART III: OPERATIONALIZING HUMAN RIGHTS IN DEVELOPMENT}

\section{Introduction to Part III}

The final section of this book focuses on "operationalizing human rights in development", by which we mean the tools that have been developed over the last half century to enhance the human rights content of development practice and the relevance of the human rights framework to the promotion of development.

The first of these tools is the essential feature of the global economy in the form of the exchange of good, services, ideas and capital across borders through international trade. It can be argued that trade constitutes one of the most intractable issues of human rights and development given the massive impact it has on the prospects for equitable distribution of the world's resources. Gillian Moon, a solicitor associated with the Australian Human Rights Institute and practicing in consumer financial services, bankruptcy and social security law, provides a complete overview of the inter-relationships between World Trade Organization (WTO) law, development and human rights. After examining 
the core principles of WTO law, she goes into depth on critical issues, such as labor rights, intellectual property and traditional knowledge before reflecting on the future prospects for elevating human rights in trade law, in the context of SDG 17 and its Target 17.10.

Varun Gauri clarifies the central concept of accountability, which is often described as the distinguishing feature of the human rights approach to development and consists in identifying rights-holders and duty-bearers and holding the latter accountable for meeting the legitimate expectations of the former. Gauri is a Lecturer of Public and International Affairs at Princeton University and was an economist in the World Bank's research department, where he founded and headed the World Bank's behavioral science unit. He is widely published on issues of human rights accountability. He proposes a typology of accountability consisting of global compliance with treaties, legal mobilization through the courts, and rights discourse. This overview of the three modes of accountability leads him to conclude that much can be gained by uncovering the interactions among them from context and social practice, including inter-subjective understandings.

The chapter on the right to development (RTD) was written by Stephen Marks, who served as chair of the Human Rights Council's High-level task force on the implementation of the right to development, and Rajeev Malhotra, who is an economist and senior civil servant and played a key role in the secretariat of the Office of the High Commissioner for Human Rights during the elaboration of human rights indicators and the attributes and criteria for the RTD. They trace that history and explore current efforts to apply human rights norms to the policies, processes and outcomes of development. The challenge they address is whether and how the use of a broad human right to development can influence development practice.

The fourth chapter in this section contains a thorough overview of the emergence and current practice of developing human rights indicators. Siobhán McInerney-Lankford and Hans-Otto Sano bring to this task a truly outstanding set of accomplishments on the topic at the World Bank and the Danish Institute for Human Rights. They not only review the contribution to the literature about human rights indicators and clarify how such indicators are distinguished from development indicators, but they explain convincingly why attention to human rights measurement calls for more efforts in light of the experience in the methodology and application of such indicators and the opportunities and risks of using new tools, such as big data and artificial intelligence.

Finally, Paul Nelson places the theme of human rights and development in the context of the 2030 Development agenda. With his background in key NGOs, as author of leading studies on human rights and development and as director of the international development program at the Graduate School of Public and International Affairs, University of Pittsburgh. Dr. Nelson reviews 
the range of perspectives in the relationship between human rights and the 2030 Development Agenda before examining the value that a human rights framework represents for monitoring and accountability for the SDGs.

Thus, this part of the book makes the case that trade, accountability, the right to development, the use of indicators and the 2030 Development Agenda provide the tools for operationalizing human rights in development. Each of these operational tools raises complex legal and political obstacles, made all the more challenging by the constraints of the second decade of the $21 \mathrm{st}$ century and are briefly mentioned in the conclusion.

\section{CONCLUSION}

The underlying challenge of all the chapters of this book is to understand whether and to what extent the paradigms, issues and tools of human rights and development can help people rise above the global threats to human survival and achieve their full potential as human beings. The world is facing four major challenges that constitute the essential background of this book: (1) the climate emergency poses an existential threat to the planet and human civilization; (2) COVID-19 is causing illness, death and massive economic disruption affecting primarily vulnerable populations; (3) extreme inequality and racial injustice keep hundreds of millions of people in extreme poverty while the wealth of the top one percent, mainly male, has grown exponentially; and (4) the rise or populist leadership and authoritarianism are weakening democratic governance across the globe. The chapters of this book, written by leading authorities on each topic, demonstrate how these four challenges are deeply interrelated and how international standards and social mobilization for human rights and sustainable development provide the normative and policy-oriented framing of the problems and the basis for action toward solutions based on justice and the equal value of all human beings. 